\title{
Mekanik Ventilasyon Tedavisi Alan Yenidoğanların Bakımında Hemşire: Eğitim ve Bilgi Düzeyi İlişkisi
}

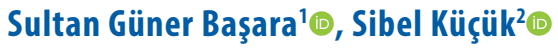

'Sağlık Bilimleri Üniversitesi, Zekai Tahir Burak Kadın Sağlığı Eğitim ve Araştırma Hastanesi, Yenidoğan Yoğun Bakım, Ankara, Türkiye

${ }^{2}$ Ankara Yıldırım Beyazıt Üniversitesi, Hemşirelik, Ankara, Türkiye

Sultan Güner Başara, Uzm. Hemşire Sibel Küçük, Dr. Öğr. Üyesi
İletişim:

Uzm. Hemşire Sultan Güner Başara

Sağlık Bilimleri Üniversitesi, Zekai Tahir Burak Kadın Sağlığı Eğitim ve Araştırma Hastanesi, Yenidoğan Yoğun Bakım, Ankara, Türkiye Tel: +902562129200

E-Posta: sgune6377@hotmail.com

\author{
Gönderilme Tarihi : $\quad 23$ Eylül 2018 \\ Revizyon Tarihi : 15 Kasım 2018 \\ Kabul Tarihi : : 15 Kasım 2018 \\ Çevrimiçi Yayın Tarihi: $\quad 04$ Mart 2020
}

\section{ÖZET}

Amaç: Araştırma altı hastanenin Yenidoğan Yoğun Bakım Üniteleri'nde (YYBÜ) çalışan 222 hemşire ile MV bakımına ilişkin bilgi durumlarının belirlenmesi amacıyla, tanımlayıcı kesitsel tipte yapılmıştır

Hastalar ve Yöntem: Altı hastanenin Yenidoğan Yoğun Bakım Üniteleri'nde (YYBÜ) çalışan 222 hemşire ile MV bakımına ilişkin bilgi durumlarının belirlenmesinde veriler veri toplama formu ile toplanmıştır. Değerlendirmede sayı, yüzde, ortalama, ki kare test istatistikleri kullanılmış, anlamlııı değeri $p<0,05$ kabul edilmiştir.

Bulgular: Hizmet içi eğitim alma, kullanılan mekanik ventilatör tipini bilme, aspirasyon sıkığının belirlenmesi, aspirasyon sırasında gelişen riskler, ağız bakımı malzemeleri, Sertifika Eğitimi ise MV pozisyonu verme, pozisyon değiştirme süresi, aspirasyonda uygulanması gereken basınç ve süreyi bilmeyi etkilemektedir $(p<0,05)$

Sonuç:Yenidoğan Yoğun Bakım Ünitesi hemşirelerinin mekanik ventilatör tedavisi sırasında, yenidoğanın pozisyon, aspirasyonu ve ağız bakımı konularındaki bilgi düzeyleri yeterli olmadığı belirlenmiştir. Hemşirelerin, sertifika ve hizmet içi eğitimleri entegre alması, uygulama protokolleri oluşturulması, uzman hemşire rehberlerin ünitede görev yapması önerilebilir.

Anahtar sözcükler: Ebeveyn, kaygı, yenidoğan, yenidoğanın geçici takipnesi

NURSE IN THE CARE OF THE NEWBORNS WITH MECHANICAL VENTILATION TREATMENT: EDUCATION AND INFORMATION LEVEL RELATIONSHIP

\section{ABSTRACT}

Purpose: A descriptive cross-sectional survey was used in order to determine nurses' level of knowledge about mechanical ventilation (MV) treatment with 222 nurses who are employees in six hospitals and work in the neonatal intensive care unit (NICU).

Patients and Methods: In order to determine nurses' level of knowledge about mechanical ventilation (MV) treatment with 222 nurses who are employees in six hospitals and work in the neonatal intensive care unit (NICU), the data were collected using the data collection form. Number, percentage, mean and chi-square test statistics were used in the assessment and a statistical significance rate of $p<0.05$ was accepted.

Results: In-service training, knowing/knowledge about the type of mechanical ventilation that is used, determining the frequency of aspiration, risks that might develop during the aspiration, oral care supplies and education certificate, on the other hand, affect the changing of MV position, the duration of changing the MV position, and also affect the knowledge of pressure and duration that are required to be applied during the aspiration $(p<0.05)$.

Conclusion: It is determined that during mechanical ventilation treatment, the knowledge of nurses working in the NICU was inadequate in terms of newborns position, aspiration and oral care. It can be recommended that getting nursing certification and in-service training integrated, creation of application protocols and working nurse expert guides in the unit. In-service training, nursing certification, creating guidelines for nurse protocols/nursing assessment protocols and being guided by an experienced nurse in the NICU are recommended.

Keywords: Parent, anxiety, newborn, transient tachypnea of newborn 
$\mathbf{Y}$ enidoğan döneminde solunum problemleri önemli mortalite ve morbidite nedenlerindendir (1). Noninvazif (NIMV) ve invazif mekanik ventilasyon (IMV) teknikleri solunum güçlüğü yaşayan ya da solunumu olmayan bebeklerin tedavisinde oksijenizasyon ve ventilasyonu sağlamak için kullanılan tekniklerin başında gelmektedir $(1,2)$

IMV tedavi etmesinin yanı sıra beraberinde Ventilatör İlişkili Pnömoni (VIP) $(\% .55,2)$, Bronkopulmoner Displazi (BPD) (1000 gr altı bebekler \%52, $1000 \mathrm{gr}$ üstü bebekte \%34) $(5,6)$, nozokomiyal enfeksiyon $(\% 24,15)$ ve pulmoner hemoraji $(\% 12,71)$ çok sık gelişen komplikasyon ve riskleri geliştirebilmektedir (3-5).

Yoğun bakım ünitelerinde yaygın kullanılan IMV uygulamasının başarısı ya da başarısızlığında en önemli faktörlerden biri de, bebeğin bakımından sorumlu hemşirenin bilgi ve becerisini doğru kullanmasından geçmektedir. Hemşirelik uygulamalarının bireysel farklılık göstermesi ve uygun olmayan yöntemlerin kullanılması, solunum tedavisini geciktirmekte ve komplikasyonları arttırmaktadır (6)

Mekanik ventilasyon tedavisi alan entübe hastanın aspirasyonuna bağlı komplikasyonların önlenebilmesi (3-5) izlemi ve uygun yatış pozisyonunun sağlanmasında yenidoğan hemşirelerinin önemli rolleri bulunmaktadır $(1,3,7,8)$.

MV'deki yenidoğanın hemşirelik bakımının ortak prosedür/protokoller doğrultusunda yapıldığında yenidoğanın ventilatörden ayrılma süresinin anlamlı derecede kısaltılabilmektedir $(9,10)$. MV protokolü geliştirilmesi için multidisipliner oluşturulmuş bir ekip, iyi düşünülmüş uygulama protokolü ve dikkatli bir uygulayıcı personel eğitimi sürecini içermesi gerekmektedir (11).

Komplikasyon yönetiminin sağlanabilmesi için solunum sıkıntısı tanısı ile mekanik ventilasyona ihtiyacı olan yenidoğanın bakımından sorumlu ekibin önemli bir üyesi olan YYBÜ'si hemşirelerinin bu risk ve komplikasyonlar konusunda eğitilmeleri, uzman hemşirelik bakımı ve enfeksiyon kontrol protokollerinin uygulanması gerekmektedir $(1,3)$. Tüm bu gerekliliklere karşın MV desteği alan yenidoğanın bakımı, hemşirelerin bilgi ve bakım uygulamaları konusunda yapılan çalışmalar yok denecek kadar azdır.

\section{Gereç ve yöntem}

Araştırmanın amacı ve tipi

Araştırma mekanik ventilasyon tedavisi alan yenidoğanların bakımında hemşirelerin bilgi durumlarının belirlenmesi amacıyla tanımlayıcı kesitsel tipte yapılmıştır.

\section{Katılımcilar}

Araştırmanın yapıldığı il merkezinde üçüncü basamakta sağlık hizmeti veren ve üçüncü düzeye YYBÜ’ne sahip altı hastane bulunmaktadır. Araştırmanın evrenini araştırmanın yapıldığı tarihlerde bu altı hastanenin Yenidoğan Yoğun Bakım Ünitesi'nde (YYBÜ) görev yapan 365 hemşire oluşturmuştur. Araştırma için herhangi bir örneklem seçimine gidilmemiş araştırmaya katılmayı gönüllü kabul eden 222 hemşire ile araştırma tamamlanmıştır.

\section{Verilerin toplanması}

Veriler 01.06.2015-01.12.2015 tarihleri arasın da araştırmacılar tarafından yüz yüze görüşme yöntemiyle toplanmıştır. Verilerin toplanmasında hemşirelere yönelik 20 kapalı uçlu sorudan oluşan 'Tanıtıcı Bilgi Formu' ve 20 kapalı uçlu sorudan oluşan 'Mekanik Ventilasyon Tedavisi Alan Yenidoğanların Hemşirelik Bakımı Bilgi Formu' kullanılmıştır. Mekanik Ventilasyon Tedavisi Alan Yenidoğanların Hemşirelik Bakımı Bilgi Formu; yenidoğanın mekanik ventilasyonu, pozisyonu verme, endotrakeal tüp aspirasyonu ve ağız bakımı bilgi durumunu sorgulamak amacıyla araştırmacılar tarafından ilgili literatür (12-17) doğrultusunda hazırlanmıştır.

Araştırmanın ön uygulaması araştırma evrenine benzer 20 hemşire ile yapılmış, gerekli düzeltmeler yapıldıktan sonra araştırmanın uygulamasına geçilmiştir. Ön uygulamaya alınan hemşireler çalışmaya dahil edilmemiştir.

\section{Verilerin değerlendirilmesi}

Değerlendirmede Shapiro-Wilks testi, ortanca Çeyreklikler Arası Genişlik-ÇAG, (InterquartileRange-IQR), Ki-Kare Karşılaştırma testi kullanılmış ve normal dağılım gösteren değişkenlere ait ortalama standart sapma (Ort \pm SS) değerleri verilmiştir. İstatistiksel anlamlılık düzeyi $p<0,05$ olarak kabul edilmiştir (IBM SPSS Statistics21,0 (IBM Corp. Released 2012. IBM SPSS Statisticsfor Windows, Version21,0. Armonk, NY: IBM Corp.) ve MS-Excel 2007).

\section{Etik}

Araştırmaya başlamadan önce gerekli yasal (Zekai Tahir Burak EAH (07.04.2015/68344250-789), Sami Ulus EAH (27.04.2015/73799008) Gazi Üniversitesi (21.04.2015/90005124-605.99), Keçiören EAH (13.05.2015/43278876/1649) Ankara Üniversitesi (27.03.2015/93984376-044-15488), Hacettepe Üniversitesi (24.07.2015/75967797-804.01/2300)) ve etik izinler (AYBÜ, 05.02.2015/16) alınmıştır. Katılımcılardan bilgilendirilmiş onam formu ile izin alınmıştır. 


\section{Tartışma}

Özel bir birimde çalışmaları nedeniyle YYBÜ hemşirelerinin kliniklerinde kullanılan cihazların işleyişi, bakım verdikleri yenidoğanın özellikleri ve bakımda dikkat edilecek noktalar gibi pek çok konuda yeterli bilgi, beceri ve donanıma sahip olmaları gerekmektedir. YYBÜ'de çalışan hemşirelerin tamamının özel bir eğitimine sahip olması gerekirken neredeyse $1 / 4$ 'ünün herhangi bir eğitime katılmadığı ve yalnızca \%45,5'nin YYB sertifikasına sahip olduğu görülmektedir (Tablo 1).

Tablo 1. Sağlık çalışanlarının sosyo-demografik ve MV ve mekanik ventilatör kullanımı eğitimi alma özellikıerinin dağılımı $(n=222)$

\begin{tabular}{|c|c|c|}
\hline Değişkenler & $n$ & $\%$ \\
\hline \multicolumn{3}{|l|}{ Cinsiyet } \\
\hline Kadın & 217 & 97,7 \\
\hline Erkek & 5 & 2,3 \\
\hline \multicolumn{3}{|l|}{ Ünvan } \\
\hline Hemşire & 168 & 75,7 \\
\hline Ebe & 54 & 24,3 \\
\hline \multicolumn{3}{|l|}{ Medeni Durum } \\
\hline Bekar & 65 & 29,3 \\
\hline Evli & 157 & 70,7 \\
\hline \multicolumn{3}{|l|}{ Öğrenim Durumu } \\
\hline Lisans & 129 & 58,1 \\
\hline Önlisans & 50 & 22,5 \\
\hline Lise & 34 & 15,3 \\
\hline Yüksek Lisans & 9 & 4,1 \\
\hline \multicolumn{3}{|l|}{ Meslekte Çalışma Yılı } \\
\hline 1 yıldan az & 7 & 3,2 \\
\hline $1-3$ yll & 40 & 18,0 \\
\hline $3-6$ yıl & 48 & 21,6 \\
\hline $6-9$ yıl & 57 & 25,7 \\
\hline 9 yıldan fazla & 70 & 31,5 \\
\hline \multicolumn{3}{|l|}{ YYBU Çalışma Yılı } \\
\hline 1 yıldan az & 27 & 12,2 \\
\hline $1-3$ yıl & 55 & 24,8 \\
\hline $3-6$ yıl & 72 & 32,4 \\
\hline $6-9$ yıl & 39 & 17,6 \\
\hline 9 yıldan fazla & 29 & 13,0 \\
\hline \multicolumn{3}{|c|}{ MV ve Mekanik Ventilatör Kullanımı Eğitimi Alma } \\
\hline Evet & 169 & 76,1 \\
\hline Hayır & 53 & 23,9 \\
\hline \multicolumn{3}{|c|}{$\begin{array}{l}\text { MV ve Mekanik Ventilatör Kullanımına İlişkin Alınan } \\
\text { Eğitim Türleri }(n=169)^{*}\end{array}$} \\
\hline Hizmet İçi Eğitim & 138 & 62,2 \\
\hline YYBÜ Sertifika Eğitimi & 101 & 45,5 \\
\hline Diğer** & 76 & 34,4 \\
\hline
\end{tabular}

Çalışmaya katılan hemşirelerin yaş ortalamasının 30,23 $\pm 5,60$ ( $\min 18-\max 46$ )'dir. \%97,7'si kadın, \%58,1'i lisansmezunu, \%31,5'i 10 yıldan fazla süredir hemşire ve \%36,0'sının ise 4-6 yıldır YYBÜ hemşiresi olarak görev yapmaktadır. Hemşirelerin \%76,1'i mekanik ventilasyon ve mekanik ventilatör kullanma eğitimini almıştır. Bu eğitimlerin ise \%62,2'siHiE, \%45,5'i SE olarak alınmıştır (Tablo 1).

Mekanik ventilatörü tanımak hastaya verilen solunum desteğinin türünü ve etkin kullanımını sağlayarak gelişebilecek komplikasyonları önlemede önemli olmasına $(18,19)$ karşın Hizmet içi eğitim (HiE) ya da Sertifika Eğitimi (SE) alan hemşirelerin önemli bir bölümü kliniklerinde kullanılan Mekanik Ventilatör tipini bilmemektedir. Kliniklerde çalışan hemşirelere kullanılan ventiatör tipinin ve özelliklerinin anlatılması nedeniyle HíE'in mekanik ventilatör tipini bilmeyi etkilediği düşünülmüştür $(p<0,05)($ Tablo 2). Kliniklerde kullanılan mekanik ventilatör tipleri farklılık gösterebilmektedir. SE'den sonra özellikle ünitelerde kullanılan Mekanik ventilatör olmak üzere farklılık gösterebilen malzemelerin kullanımının HiE'de ele alınmasının önemli olduğu görülmektedir. (Tablo 2).

YYBÜ'de yenidoğanların klinik tedavilerinin uygulanmasında hemşirelerin gözlem ve izlemleri önemlidir. Mekanik ventilasyon endikasyonlarının $(20,21)$ belirlenmesi ve oksijen konsantrasyonu yönetiminde yenidoğanı yakından takip eden ve değerlendiren hemşirelere önemli sorumluluk düşmektedir (20,22,23). Yenidoğanın Mekanik Ventilasyon (MV) endikasyonlarını ve komplikasyonlarını $(20,21)$ alınan eğitim türüne bağlı olmaksızın bilme oranları çok düşüktür (Tablo 2). Hemşirelerin konu hakkında bilgilerinin oldukça düşük olması komplikasyonları artırabilecek bir faktör olabilir.

Mekanik ventilasyon tedavisi alan yenidoğanın sürekli aynı pozisyonda yatırıması kısa sürede deri bütünlüğünü bozabilmektedir. Bu nedenle hastanın pozisyon değişimi, sıklığı ve şekli korunması açısından önemlidir (15). Prone pozisyonunun kullanılması $(8,24), 2-3$ saat ara ile pozisyon değiştirilmesi önerilmektedir $(15,18,25)$. Hemşirelerin alınan eğitim türüne bakılmaksızın yarııından fazlasının MV'daki yenidoğanı doğru pozisyonlarda takip ettikleri ve doğru sürelerde pozisyon değiştirdikleri ve SE alma ile MV pozisyonu ve süresini bilmeyi etkilediği belirlenmiştir $(p<0,05)$ (Tablo 2). Herhangi bir eğitim almayanların eğitim alan hemşirelerden yüksek oranda pozisyon değiştirme süresini bilmeleri anlamlıdır.

Mekanik ventilatör tedavisi nedenleri ve komplikasyonlarını bilme oranı düşüktür. Tedavi sırasında verilmesi gereken pozisyon ve pozisyon değiştirme süreleri yanıtlarının oranı 
Tablo 2. YYBÜ'de çalışan hemşirelerin aldıkları eğitim ile yenidoğanların MV tedavisi ve pozisyonlarına yönelik bilgilerinin karşılaştırıması ( $\mathrm{n}=222)$

\begin{tabular}{|c|c|c|c|c|c|c|c|c|}
\hline & \multicolumn{4}{|c|}{ Hizmet İçi eğitim (HiE) } & \multicolumn{4}{|c|}{ Sertifika Eğitimi (SE) } \\
\hline & \multicolumn{2}{|c|}{ Alan } & \multicolumn{2}{|c|}{ Almayan } & \multicolumn{2}{|c|}{ Alan } & \multicolumn{2}{|c|}{ Almayan } \\
\hline & $n$ & $\%$ & $n$ & $\%$ & $n$ & $\%$ & $n$ & $\%$ \\
\hline \multicolumn{9}{|c|}{ Ünitede kullanılan MV Tipi } \\
\hline Bilen & 85 & 62,8 & 38 & 45,2 & 60 & 40,0 & 40 & 42,1 \\
\hline Bilmeyen & 38 & 45,2 & 46 & 54,8 & 63 & 60,0 & 58 & 57,9 \\
\hline Test ve p değeri & \multicolumn{4}{|c|}{$X^{2}=5,959, \mathbf{p}=\mathbf{0 , 0 1 5}$} & \multicolumn{4}{|c|}{$X^{2}=1,396, p=0,237$} \\
\hline \multicolumn{9}{|c|}{ Mekanik ventilasyon desteği nedeni } \\
\hline Bilen & 8 & 5,8 & 1 & 1,2 & 6 & 5,9 & 3 & 2,5 \\
\hline Bilmeyen & 13 & 94,2 & 82 & 98,8 & 95 & 94,1 & 117 & 97,5 \\
\hline Test ve p değeri & \multicolumn{4}{|c|}{$x^{2}=$ Fisher's exact $^{\star \star}, p=0,088$} & \multicolumn{4}{|c|}{$X^{2}=$ Fisher's exact $^{\star \star}, p=0,172$} \\
\hline \multicolumn{9}{|l|}{ Komplikasyonlar } \\
\hline Bilen & 15 & 11,2 & 4 & 4,9 & 13 & 13,1 & 6 & 5,2 \\
\hline Bilmeyen & 119 & 88,8 & 77 & 95,1 & 86 & 86,9 & 110 & 94,8 \\
\hline Analiz & \multicolumn{4}{|c|}{$X^{2}=1,737, p=0,187$} & \multicolumn{4}{|c|}{$X^{2}=3,270, p=0,071$} \\
\hline \multicolumn{9}{|l|}{ Pozisyon verme } \\
\hline Bilen & 64 & 56,6 & 47 & 43,9 & 56 & 59,6 & 55 & 43,7 \\
\hline Bilmeyen & 49 & 43,4 & 60 & 56,1 & 38 & 40,4 & 71 & 56,3 \\
\hline Test ve p değeri & \multicolumn{4}{|c|}{$X^{2}=3,553, p=0,059$} & \multicolumn{4}{|c|}{$X^{2}=5,461, p=0,019$} \\
\hline \multicolumn{9}{|c|}{ Pozisyon değiştirme süresi } \\
\hline Bilen & 77 & 68,1 & 79 & 73,1 & 59 & 62,8 & 97 & 76,4 \\
\hline Bilmeyen & 36 & 31,9 & 29 & 26,9 & 35 & 37,2 & 30 & 23,6 \\
\hline Test ve p değeri & \multicolumn{4}{|c|}{$X^{2}=0,667, p=0,414$} & \multicolumn{4}{|c|}{$X^{2}=4,821, p=0,028$} \\
\hline
\end{tabular}

benzerdir. HiE alma ile kullanılan mekanik ventilatör tipini bilme, SE alma verilmesi gereken pozisyon ve pozisyon değiştirme süresi arasında anlamlı ilişki vardır $(p<0,05)$ (Tablo 2$)$.

Uygun yöntemle yapılmayan aspirasyon pek çok komplikasyona neden olabildiğinden $(26,27)$ aspirasyon basıncı, süresinin dikkatli takip edilmesi, gerektikçe ve doğru pozisyonda aspirasyon yapılması önerilmektedir $(11,26,28,29)$. Aspirasyonda kişisel hasta değerlendirmesi (30) ve acil aspirasyon gereksinimlerinin bilinmesi de önemlidir (28). Hemşirelerin çoğunluğu ihtiyaç oldukça aspirasyon yapılması gerektiğini ve doğru aspirasyon tekniğini bilmektedir. Aspirasyonda uygulanan basınç ve süreyi doğru bilme eğitim alanlarda yüksek olsa da (Tablo 3) aspirasyon gibi rutin uygulanan bir işlemin nasıl uygulanması gerektiğini bilmeyen hemşirelerin bulunması düşündürücüdür.

Aspirasyon işleminin aseptik teknikle, uygun boyutta katater ile iki kişi tarafından ve trakeal önceden ölçülerek yapılması gerekmektedir. Solunum sekresyonlarından korunmak amacıyla koruyucu önlük, maske ve gözlük kullanılması önerilmektedir (31).

Endotrakeal aspirasyonda SF kullanılması oksijen satürasyonunda azalma, intrakranial ve kardiyak değişikliklere ve nazokomiyal enfeksiyonlara neden olabildiği için çok yoğun sekresyon varlığı dışında kullanılmamalıdır (32-35). Eğitim türüne bakılmaksızın hastanın primer bakımından sorumlu ve hava yolu açıklığının sağlanmasında en temel yetkili olan hemşirelerin acil aspirasyon ihtiyacın nedenleri, kullanılan malzemeler, pozisyon ve aspirasyon sırasında gelişebilecek risklere ilişkin bilgi düzeyleri oldukça düşük olması (Tablo 3) aspirasyona bağlı olası komplikasyon risklerinin artmasına neden olabilir.

Mekanik ventilasyondaki yenidoğanın bakımında bir diğer önemli konu ağız bakımıdır. Doğru açı, hat, süre ve malzeme ve sıralama ile ağız bakımı verilmesi önemlidir $(33,36)$. 
Tablo 3. YYBÜ'de çalışan hemşirelerin aldıkları eğitim ile MV tedavisi alan yenidoğanların aspirasyonuna yönelik bilgilerinin karşılaştıılması ( $\mathrm{n}=222$ )

\begin{tabular}{|c|c|c|c|c|c|c|c|c|}
\hline & \multicolumn{4}{|c|}{ Hizmet İçi eğitim (HiE) } & \multicolumn{4}{|c|}{ Sertifika Eğitimi (SE) } \\
\hline & \multicolumn{2}{|c|}{ Alan } & \multicolumn{2}{|c|}{ Almayan } & \multicolumn{2}{|c|}{ Alan } & \multicolumn{2}{|c|}{ Almayan } \\
\hline & $n$ & $\%$ & $n$ & $\%$ & $n$ & $\%$ & $n$ & $\%$ \\
\hline \multicolumn{9}{|l|}{ Sıklık } \\
\hline Bilen & 128 & 92,1 & 66 & 80,5 & 86 & 91,5 & 108 & 85,0 \\
\hline Bilmeyen & 11 & 7,9 & 16 & 19,5 & 8 & 8,5 & 19 & 15,0 \\
\hline Test ve p değeri & \multicolumn{4}{|c|}{$X^{2}=5,433, p=0,020$} & \multicolumn{4}{|c|}{$X^{2}=1,537, p=0,216$} \\
\hline \multicolumn{9}{|l|}{ Basınç ve süre } \\
\hline Bilen & 77 & 60,2 & 37 & 48,7 & 61 & 68,5 & 53 & 46,1 \\
\hline Bilmeyen & 51 & 39,8 & 39 & 51,3 & 28 & 31,5 & 62 & 53,9 \\
\hline Test ve p değeri & \multicolumn{4}{|c|}{$X^{2}=2,546, p=0,111$} & \multicolumn{4}{|c|}{$X^{2}=10,25, p=0,002$} \\
\hline \multicolumn{9}{|c|}{ Kullanılan malzeme } \\
\hline Bilen & 2 & 1,4 & 1 & 1,2 & 3 & 3,2 & 0 & 0,0 \\
\hline Bilmeyen & 138 & 98,6 & 81 & 98,8 & 9 & 96,8 & 128 & 100 \\
\hline Test ve p değeri & \multicolumn{4}{|c|}{$X^{2}=0,017, p=0,896$} & \multicolumn{4}{|c|}{$X^{2}=$ Fisher's exact ${ }^{\star *} p=0,075$} \\
\hline \multicolumn{9}{|c|}{ Aspirasyon sırasında gelişen riskler } \\
\hline Bilen & 37 & 28,2 & 13 & 16,0 & 17 & 18,3 & 33 & 27,7 \\
\hline Bilmeyen & 94 & 71,8 & 68 & 84,0 & 76 & 81,7 & 86 & 72,3 \\
\hline Test ve p değeri & \multicolumn{4}{|c|}{$X^{2}=4,130, p=0,042$} & \multicolumn{4}{|c|}{$X^{2}=1,827, p=0,768$} \\
\hline \multicolumn{9}{|c|}{ Acil aspirasyon nedenleri } \\
\hline Bilen & 8 & 5,8 & 1 & 1,2 & 5 & 5,3 & 4 & 3,1 \\
\hline Bilmeyen & 131 & 94,2 & 81 & 98,8 & 89 & 94,7 & 132 & 96,9 \\
\hline Test ve $\mathbf{p}$ değeri & \multicolumn{4}{|c|}{$X^{2}=2,716, p=0,099$} & \multicolumn{4}{|c|}{$X^{2}=$ Fisher's exact, $p=0,50$} \\
\hline \multicolumn{9}{|l|}{ Pozisyon } \\
\hline Bilen & 12 & 8,8 & 9 & 11,1 & 10 & 11,0 & 11 & 8,7 \\
\hline Bilmeyen & 125 & 91,2 & 72 & 88,9 & 81 & 89,0 & 16 & 91,3 \\
\hline Test ve p değeri & \multicolumn{4}{|c|}{$X^{2}=0,110, p=0,740$} & \multicolumn{4}{|c|}{$X^{2}=$ Fisher's exact ${ }^{\star \star}, p=0,180$} \\
\hline
\end{tabular}

HiE ve SE alan hemşirelerin MV tedavisi alan bebeğin aspirasyon yapılma sıklığı ve basınç ve süreyi bilme oranları yüksek, kullanılan malzeme, aspirasyon sırasında gelişen riskler, acil aspirasyon nedenleri ve pozisyonu bilme oranları düşüktür. HíE alma ile aspirasyon sıkığının belirlenmesi, SE alma ile aspirasyon sırasında gelişen riskler ve aspirasyon basıncı ve süresi arasında anlamlı fark vardır $(p<005)$ (Tablo 3).

Hemşirelerin eğitim almaları ağız bakımın planlanması ve doğru pozisyon konularında anlamlı bir fark oluşturmamaktadır ( $p>0,05)$. Bakım sırasında verilmesi gereken pozisyon ise genellikle bilmemektedir (Tablo 3). Ağız bakımı için kullanılması gereken malzemelerin (34) bilinme oranlarını her iki eğitimi alan hemşirelerde almayanlara göre yüksek olmasına karşın HiE alma kullanılan malzemelere verilen doğru yanıtları etkilemektedir $(p<0,05)$ (Tablo 4).

Literatürde MV desteği alan yenidoğanın bakımı, hemşirelerin bilgi ve bakım uygulamaları konusunda yapılan çalışmaların yok denecek kadar az olması verilerin karşılaştırılmasını zorlaştırmıştır.

Ağız bakımı sırasında verilmesi gereken pozisyon ve kullanılan malzemeleri bilme oranları düşüktür. Ağız bakının planlanması ve aspirasyon ihtiyacına karar verme yanıtları her iki eğitimi alanlarda benzerdir. HiE alma, kullanılan malzemeleri bilmeyi etkilemektedir $(p<0,05)$ (Tablo 4). 
Tablo 4. YYBÜ'de çalışan hemşirelerin aldıkları eğitim ile MV tedavisi alan yenidoğanların ağız bakımına yönelik bilgilerinin karşılaştıııması ( $n=222)$

\begin{tabular}{|c|c|c|c|c|c|c|c|c|}
\hline & \multicolumn{4}{|c|}{ Hizmet Içi eğitim (HiE) } & \multicolumn{4}{|c|}{ Sertifika Eğitimi (SE) } \\
\hline & \multicolumn{2}{|c|}{ Alan } & \multicolumn{2}{|c|}{ Almayan } & \multicolumn{2}{|c|}{ Alan } & \multicolumn{2}{|c|}{ Almayan } \\
\hline & $n$ & $\%$ & $n$ & $\%$ & $n$ & $\%$ & $n$ & $\%$ \\
\hline \multicolumn{9}{|l|}{ Pozisyon } \\
\hline Bilen & 22 & 16,9 & 7 & 8,5 & 22 & 13,5 & 17 & 13,8 \\
\hline Bilmeyen & 108 & 83,1 & 75 & 91,5 & 77 & 86,5 & 106 & 86,2 \\
\hline Test ve p değeri & \multicolumn{4}{|c|}{$X^{2}=2,327, p=0,127$} & \multicolumn{4}{|c|}{$X^{2}=0,005, p=0,944$} \\
\hline \multicolumn{9}{|c|}{ Bakımın planlanması } \\
\hline Bilen & 116 & 89,2 & 72 & 83,7 & 79 & 90,2 & 109 & 84,5 \\
\hline Bilmeyen & 14 & 10,8 & 14 & 16,3 & 8 & 9,8 & 20 & 15,5 \\
\hline Test ve p değeri & \multicolumn{4}{|c|}{$X^{2}=0,947, p=0,330$} & \multicolumn{4}{|c|}{$X^{2}=1,316, p=0,251$} \\
\hline \multicolumn{9}{|c|}{ Aspirasyon ihtiyacı } \\
\hline Bilen & 102 & 77,9 & 68 & 78,2 & 70 & 76,9 & 100 & 78,7 \\
\hline Bilmeyen & 29 & 22,1 & 9 & 21,8 & 21 & 23,1 & 27 & 27,3 \\
\hline Test ve p değeri & \multicolumn{4}{|c|}{$X^{2}=0,000, p=1,000$} & \multicolumn{4}{|c|}{$X^{2}=0,024, p=0,878$} \\
\hline \multicolumn{9}{|c|}{ Kullanılan malzeme } \\
\hline Bilen & 34 & 25,2 & 10 & 11,6 & 19 & 20,7 & 25 & 19,4 \\
\hline Bilmeyen & 101 & 74,8 & 76 & 88,4 & 73 & 79,3 & 106 & 80,6 \\
\hline Test ve p değeri & \multicolumn{4}{|c|}{$X^{2}=5,235, p=\mathbf{0 , 0 2 2}$} & \multicolumn{4}{|c|}{$X^{2}=0,004, p=0,950$} \\
\hline
\end{tabular}

\section{Sonuç}

YYBÜ hemşirelerinin MV tedavisi alan yenidoğanın pozisyonu, aspirasyonu ve ağız bakımına ilişkin eğitimleri yetersizdir. Sertifika veya hizmet içi eğitimleri tek başına bilgi düzeyini yükseltmede yeterli değildir. YYBÜ hemşirelerinin SE almalarının yanı sıra belirli aralıklarla hizmet içi eğitimlere

\section{Kaynaklar}

1. Başkan AK, Salihoğlu Ö, Tan İ, Akyol B, Hatipoğlu S. İnvaziv Mekanik Ventilatör Desteği Alan Yenidoğanlarda Morbidite ve Mortalite Analizi. J Clin Exp Invest 2012;3:483-92. [CrossRef]

2. Patil MB, Sandeep V, Harish G, Patil MV, Vijayanath V. Mechanical Ventilation in Neonates. Int J Pharm Biol Sci 2013;3:50-6. https:// www.ijpbs.com $/$ previousissue.php?year $=2013$ \&issue $=2$

3. Khattab AA, Lahony DM, Soliman WF. Ventilator-associated Pneumonia in The Neonatal Intensive Care Unit. Menoufia Med J 2014;27:73-7. [CrossRef]

4. Bernbaum J. Chronic Lung Disease. In: MacDonald MG, Seshia MMK, Mullet MD, editors. Avery's Neonatology, 6th edition. Philadelphia: Lippincott Williams\&Wilkins 2005;1625-31.

5. Akdağ A, Uraş N, Dilmen U. Bronkopulmoner Displaziye Güncel Yaklaşım. Türk Çocuk Hastalıkları Derg 2012;6:185-93. https:// dergipark.org.tr/tr/download/article-file/688998

6. Chen CY, Chou AK, Chen YL, Chou HC, Tsao PN, Hsieh WS, Quality improvement of nasal continuous positive airway pressure therapy in neonatal intensive care unit. Pediatr Neonatol 2017;58:229-35. [CrossRef] katılmaları, entegre eğitim almaları bilgi düzeylerini arttırmalarına katkı sağlayabilecektir. MV'daki yenidoğanın bakımı konularında verilen eğitimlerin sıklığının ve niteliğinin arttırılması, YYBÜ'de uygulanan hemşirelik bakımı protokollerinin kullanılması ve konu hakkında uzman hemşire rehberlerin ünitede görev yapması önerilebilir.

7. Abdeyazdan Z, Nematollahi M, Ghazavi Z, Mohhamadizadeh M, The effects of Supine and Prone Positions on Oxygenation in Premature Infants Undergoing Mechanical Ventilation. Iran J Nurs Midwifery Res 2010;15:229-33. https://www.ncbi.nlm.nih.gov/pmc/articles/ PMC3203282/

8. Atıcı A, Özkan H, Yenidoğan Bebeğin Mekanik Ventilasyonu. Adana: Nobel Kitapevi; 2011. s.44, 91, 92.

9. SHR Nursing Practice Committee. Suctioning - Pediatric/Neonate Patients Ventilated (Conventional and High Frequency) via Artificial Airways. 2017. https://www.saskatoonhealthregion.ca/about/ nursingmanual/1056.pdf

10. Ünal S. Sağlık Hizmetleri İle Illişkili Pnömoninin Önlenmesi Kılavuzu. Hastane İnfeksiyonları Derg 2008;12-2. http://www.hider.org.tr/ global/Dernek_Kilavuzlari/2008-12-Ek2-003-014.pdf

11. Sant'Anna GM, Keszler M, Developing a Neonatal Unit Ventilation Protocol for The Preterm Baby. Early Hum Dev 2012;88:925-9. [CrossRef]

12. Spence K, Barr P. Nasal Versus Oral Intubation for Mechanical Ventilation of Newborn Infants Cochrane Database Syst Rev 2000;2000:CD000948. 
13. Lantos JD, Feudtner C. Support and the Ethics of Study Implementation: Lessons for Comparative Effectiveness Research from the Trial of Oxygen Therapy for Premature Babies. Hastings Cent Rep 2015;45:30-40. [CrossRef]

14. Tanman B. Fetal ve Neonatal Dolaşım. Neyzi O, Ertuğrul T, editörler. Pediatri 2. Baskı. Cilt 2. İstanbul: Tayt Ofset; 1993. p.237-8.

15. Dağoğlu T, Ovalı F. Neonatoloji. İstanbul: Nobel Tıp Kitapevleri; 2007. s.226, 230, 352, 386, 411, 417, 412, 427, 437, 438.

16. Yurdakök M, Yiğit Ş, Tekinalp G. Yenidoğanda Solnum Desteği. Ankara: Güneş Kitapevi; 2005. s.63, 64, 65, 103, 122, 219, 220.

17. Lund $\mathrm{CH}$. Nursing Care. In: Goldsmith J, Karotkin E, editors. Assisted Ventilation of the Neonate, 5th ed. Philadelphia: Elsevier, Inc.; 2010. p.126-39.

18. Atıcı A, Turhan AH, Çelik Y, Özkan BA, Kotan Ç. Yenidoğanda Volüm Garantili Ventilasyon ile Basınç Kontrollü Ventilasyonun Karşılaştırılması. Türk Ped Arş 2010;45:324-8.

19. Arman Bilir Ö, Ünal S, Özaydın E, Çakmak Çelik F. Yenidoğanda Mekanik Ventilasyon Desteği: Endikasyonlar, Komplikasyonlar ve Prognoz. Türkiye Çocuk Hast Derg 2009;3:46-52. https://dergipark. org.tr/en/download/article-file/690173

20. Amini E, Nayeri FS, Hemati A, Esmaeilinia T, Nili F, Dalili H, Aminnejad M. Comparison of High Frequency Positive Pressure Mechanical Ventilation (HFPPV) With Conventional Method in the Treatment of Neonatal Respiratory Failure. Iran Red Crescent Med J 2013;15:1836. [CrossRef]

21. Sağlık Bakanlığı Hizmet İçi Eğitim Yönetmeliği 11/12/2009 tarih ve 15296 sayılı Bakanlık Makam Onayı, 21 Ağustos 2010 tarih 27679 sayılı Resmi Gazete'de Yayınlanan Sağlık Bakanlığı Sertifikalı Eğitim Yönetmeliği.

22. Kumar A, Bhat BV. Epidemiology of Respiratory Distress of Newborns. Indian J Pediatr 1996;63:93-8. [CrossRef]

23. Annagür A, Altunhan $H$, Arıbaş $S$, Konak $M$, Koç $H$, Örs R. Yenidoğan Yoğun Bakım Ünitesine Solunum Sıkıntısı Nedeniyle Yatan Hastaların Retrospektif Olarak Değerlendirilmesi. Çukurova Üniversitesi Tıp Fakültesi Derg 2012;37:90. https://dergipark.org.tr/tr/download/ article-file/47368

24. Özkan H, Yenidoğanda Solunum Fizyolojisi, Mekanik Ventilasyon Endikasyonları, Başlangıç Ayarları. Güncel Pediatri 2006;4:102-4.
25. Aydın D, Çiftçi EK. Yenidoğan Yoğun Bakım Hemşirelerinin Preterm Yenidoğanlara Uygulanacak Teröpatik Pozisyonlar Hakkında Bilgi Düzeyi. Güncel Pediatri 2015;13:21-30. https://dergipark.org.tr/tr/ download/article-file/903752

26. Harpin VA, Rutter N, Barrier Roperties of The Newborn Infant's Skin. J Pediatr 1983;102:419-25. [CrossRef]

27. Chen SS, Tzeng YL, Gau BS, Kuo PC, Chen JY. Effects of Prone and Supine Positioning on Gastric Residuals in Preterm Infants: a time series with cross-over study. Int J Nurs Stud 2013;50:1459-67. [CrossRef]

28. Young J. To help or hinder: Endotracheal Suction and the Intubated Neonate. J Neonat Nurs 1995;1:23-8.

29. McLane KM, Bookout K, McCord S, McCain J, Jefferson LS. The 2003 National Pediatric Pressure Ulcer and Skin Breakdown Prevalence Survey: a multisite study. J Wound Ostomy and Continence Nurs 2004;31:168-78. [CrossRef]

31. Gonçalves RL, Tsuzuki LM, Santos Carvalho MG. Endotracheal suctioning in Intubated Newborns: an integrative literature review. Rev Bras Ter Intensiva 2015;27:284-92. [CrossRef]

32. Gardner D, Shirland L. Evidence-Based Guideline for Suctioning the Intubated Neonate and Infant Neonatal Network 2009;28:281-302. [CrossRef]

33. Akgül Çelik S, Kanan NA, Current Conflict: Use of Isotonic Sodium Chloride Solution on Endotracheal Suctioning in Critically III Patients. Dimens Crit Care Nurs 2006;25:11-4. [CrossRef]

34. Ridling DA, Martin LD, Bratton SL. From Children's Hospital and Regional Medical Center, Seattle Wash. Endotracheal Suctioning with or without Instillation of Isotonic Sodium Chloride Solution in Critically III Children. Am J Crit Care 2003;12:212-9. [CrossRef]

35. Özden D, Taş Z, Yıldız M. Hemşirelerin Açık ve Kapalı Sistem Aspirasyon Yönteminde Serum Fizyolojik Uygulama Durumlarının ve Nedenlerinin Belirlenmesi. HEMAR-G 2009;3:18-29. http://hemarge. org.tr/ckfinder/userfiles/files/2009/2009-vol11-sayi3-222.pdf

36. Institutional Policy and Procedure. http://www.cbahi.org/rm/files/ Standards/L\&D/Sample/06\&07\%20L\&D\%20ETT\%20Suctioning\%20 in\%20InfantsC.pdf

37. Drews MB, Ludwing AC, Leititis JU, Daschner FD. Low Birth Weight and Nosocomial Infection of Neonatal in a Neonatal Intensive Care Unit. J Hospt Infect 1995;30:65-72. [CrossRef] 